\title{
"Det bygger liksom på att man vet sammanhanget": Elevers resonemang om syntaktisk (o)fullständighet i en skönlitterär text
}

\author{
Agnes Strandberg^ \& Outi Toropainen \\ Luleå tekniska universitet, Sverige
}

\begin{abstract}
Abstrakt
Inom ramen för en kontextualiserad grammatikundervisning utforskar och analyserar den här artikeln svenska gymnasieelevers metalingvistiska aktiviteter där de resonerar om ett skönlitterärt textutdrag. En induktiv innehållsanalys genomfördes i syfte att belysa på vilka sätt tre elevgrupper resonerar om huvudsatsformade och icke huvudsatsformade meningar i ett textutdrag ur Stina Jacksons roman Silvervägen. Resultatet visar, i likhet med tidigare studier, att elevernas resonemang i första hand stödjs av minnesregler och betydelser, vilket kan försvåra igenkännandet av den syntaktiska (o)fullständigheten. När eleverna kopplar samman meningarna till kringliggande meningar lyckas de emellertid känna igen den syntaktiska (o)fullständigheten. Även om ett betydelsemässigt fokus kan förhindra eleverna att identifiera och förklara grammatiska strukturer visar resultatet att utgångspunkten i att textuellt knyta an meningar, såväl syntaktiskt som semantiskt, kan stötta eleverna i resonemang rörande syntaktisk (o)fullständighet. Resultatet pekar vidare på att en utgångspunkt i skönlitterära texter och syntaktisk (o)fullständighet kan fungera som en deskriptiv ingång för att synliggöra och diskutera språkliga strukturer och konventioner i förstaspråksundervisningen.
\end{abstract}

Nyckelord: kontextualiserad grammatikundervisning; metalingvistiska aktiviteter; metasyntaktiska resonemang; gruppsamtal; L1; gymnasieskolan

\begin{abstract}
"You really need to know the context": Students' discussion about syntactic (in)completeness in a literary text

Within the framework of a contextualized view of grammar teaching, this paper explores and analyzes metalinguistic activities in which Swedish upper secondary school students (aged 15-17) discuss a fictional text (Stina Jackson's novel The Silver Road) and its syntactical components. In order to shed light on the students' reflections about syntactical (in)completeness, an inductive content analysis was carried out. The findings show that the students primarily used rules of thumb and semantic associations in their reflections, which can complicate the recognition of syntactically (in)complete sentences. However, when they considered the sentences as linked together
\end{abstract}

^Korrespondens: Agnes Strandberg, e-post: agnes.strandberg@1tu.se

(C) 2022 Agnes Strandberg \& Outi Toropainen. This is an Open Access article distributed under the terms of the Creative Commons Attribution 4.0 International License (https://creativecommons.org/licenses/BY/4.0/), allowing third parties to copy and redistribute the material in any medium or format and to remix, transform, and build upon the material for any purpose, even commercially, provided the original work is properly cited and states its license.

Citation: A. Strandberg $\mathcal{E}$ O. Toropainen. "Det bygger liksom på att man vet sammanhanget”: Elevers resonemang om syntaktisk 


\section{A. Strandberg E् O. Toropainen}

textually, they succeeded in recognizing syntactic (in)completeness. While using semantic associations can make the identification and explanation of grammatical structures more difficult, the results indicate that students' reflections about syntactic (in)completeness can be facilitated by considering both syntactical and semantic cohesion in texts. Finally, the present study shows the potential of a contextualized grammar teaching, as it explores how fictional texts and syntactic (in) completeness can function as starting points for grammar teaching and thus support a descriptive approach to linguistic structures and conventions in the first language classroom.

Keywords: contextualized grammar teaching; metalinguistic activity; metasyntactic reflection; group discussion; L1; upper secondary school

Responsible editor: Arild M. Bakken

Received: June, 2021; Accepted: December, 2021; Published: January, 2022

\section{Inledning}

Den här studien handlar om gymnasieelevers resonemang om syntaktisk (o)fullständighet, mer specifikt huvudsatsformade och icke huvudsatsformade meningar, i ett skönlitterärt textutdrag. Studien är en del av ett större designbaserat forskningsprojekt där grammatikundervisningen i tre iterationer integreras i olika innehållsmoment i svenskundervisningen med syftet att öka elevers språkliga medvetenhet. Föreliggande material är hämtat från designens första cykel, där grammatikundervisningen kopplas samman till arbete med skönlitterära texter.

Under det senaste årtiondet har en kontextualiserad grammatikundervisning fått genomslag i förstaspråkämnet (Kabel \& Bjerre, 2020; Myhill et al., 2012). En kontextualiserad grammatikundervisning utgår bland annat från ett deskriptivt utforskande av autentiska texter och betonar vikten av att språk, och därmed grammatik, bör förstås och analyseras i en kontext (Myhill et al., 2013). Detta kan ses som en motreaktion på att grammatikundervisningen länge har präglats av ett dekontextualiserat drillande av ordklasser och satsdelar, som elever generellt sett har upplevt som irrelevant (Denham, 2020; Kabel et al., 2021; Strzelecka \& Boström, 2014; Watson, 2012). Myhill et al. (2020) menar att detta delvis kan förstås utifrån avsaknaden av ett kommunikativt sammanhang, eftersom kopplingen mellan kunskap om språkets struktur och autentiskt språkbruk har varit vag (se även Malmberg, 2020). Tidigare forskning om kontextualiserad grammatikundervisning tenderar emellertid att i första hand uppfatta grammatiken som ett verktyg för skrivande, och fokuserar därmed primärt på elevers efterföljande skriftproduktion (t.ex. Arseneau et al., 2018; Myhill et al., 2020). Eftersom språket är människans främsta kännetecken och eftersom kunskap om svenska språkets uppbyggnad, det vill säga ord, fraser och satsers struktur, utgör ett centralt innehåll i svenskundervisningen (Skolverket, 2011), borde grammatikundervisningen även fokusera på elevers kunskapande där grammatikens intrinsikala värden aktualiseras. Den här artikeln fokuserar därför på elevers metalingvistiska aktiviteter där de samtalar om språkets struktur i en skönlitterär text. 
Att koppla samman grammatikundervisning till utforskandet av skönlitterära texter kan utveckla elevers förståelse för språkets variationsrikedom (jfr Cushing, 2018), och samtidigt skapa en inramning för grammatiken. Skönlitterära texter innehåller nämligen syntaktiskt varierade satser och meningar och är inte lika låsta vid språkliga normer som exempelvis sakprosa. Enligt Schuster (2006) kan utforskandet av icke huvudsatsformade meningar utveckla elevers förståelse för hur språk strukturellt fungerar, exempelvis vad som grammatiskt konstituerar en sats, samt hur grammatik kan användas för att skapa en stilistisk effekt (se även Wilson, 2000). En undersökning som fokuserar på elevers metalingvistiska aktiviteter om ett skönlitterärt språkmaterial innehållande syntaktisk (o)fullständighet kan på så sätt bidra med insikter om skönlitteraturens didaktiska potential för en kontextualiserad grammatikundervisning. Tidigare forskning påvisar dessutom att elever har svårt för att resonera om texter utifrån ett syntaktiskt perspektiv (Watson \& Newman, 2017). Det är därför relevant att belysa elevers resonemang om syntaktisk (o)fullständighet för att få kunskap om vilka tillvägagångssätt elever kan aktualisera för att diskutera språkets strukturella egenskaper. Med hjälp av sådan kunskap kan lärare i sin tur utveckla undervisningen samt bemöta de möjligheter och utmaningar som de olika tillvägagångssätten kan generera.

I den här artikeln analyseras tre elevgruppers videoinspelade metalingvistiska aktiviteter i gymnasieskolans svenskundervisning. Tillsammans utforskar grupperna syntaxen i ett textutdrag ur Stina Jacksons spänningsroman Silvervägen. Syftet med artikeln är att bidra med kunskap om gymnasieelevers resonemang om syntaktisk (o)fullständighet inom ramen för en kontextualiserad grammatikundervisning. Artikeln avser därför besvara följande frågeställning:

- På vilka sätt resonerar eleverna om den syntaktiska (o)fullständigheten i textutdraget?

\section{Bakgrund}

\section{Metalingvistiska aktiviteter}

I den här artikeln analyseras elevers metalingvistiska aktiviteter, med särskilt fokus på elevers resonemang rörande syntaktisk (o)fullständighet. I linje med Camps och Fontich (2019) definieras en metalingvistisk aktivitet som den verbala eller icke verbala aktivitet som har det muntliga eller skriftliga språket själv som underlag för observation, reflektion och analys. Termen metalingvistisk syftar således på "the use of language to refer to itself" (Gombert, 1992, s. 4), vilket kretsar kring interaktiva aktiviteter av reflektion om språk i användning. Precis som språket förvärvas genom interaktion med individerna som talar det, menar Fontich och Camps (2014) att förmågan att observera, manipulera och reflektera över det också utvecklas genom interaktion. För att bli medvetna språkanvändare behöver elever vidare explicit undersöka språk som ett studieobjekt, och där utgör analys av skriftspråk ett centralt medium eftersom det innebär att språket lyfts fram som ett objekt för observation och reflektion inom en autentisk språklig kontext (Fontich \& Camps, 2014). Under metalingvistiska aktiviteter kan elever exempelvis tillsammans utforska och resonera om den grammatiska strukturen $i$ en text, och på så sätt förvärva explicita kunskaper om språk (jfr Carter, 2003). 


\section{A. Strandberg E् O. Toropainen}

Att interaktivt utforska och analysera språkliga strukturer i en viss kontext utgör vidare ett centralt inslag av en kontextualiserad grammatikundervisning (Myhill et al., 2013). Här betonar emellertid Myhill et al. (2013) även vikten av att koppla samman en grammatisk struktur med dess betydelse och effekt $i$ ett visst sammanhang. Inom ramen för en kontextualiserad grammatikundervisning kan metalingvistiska aktiviteter därför innefatta resonemang om språk ur varierade perspektiv. De kan fokusera på hur fonem bildar ord (metafonologiska resonemang), på ords struktur och betydelse (metalexikala och metasemantiska resonemang), på satser och meningar (metasyntaktiska resonemang), på textstruktur (metatextuella), eller på den språkliga kontexten (metapragmatiska resonemang) (Gombert, 1992; Watson \& Newman, 2017). För att kunna göra kopplingar mellan en grammatisk struktur och dess betydelse och effekt, behöver eleverna kunna identifiera strukturen (jfr Myhill et al., 2013). Den här studien fokuserar därför på elevers metasyntaktiska resonemang, alltså när de medvetet resonerar om språkets syntaktiska egenskaper (Gombert, 1992), vilket i denna studie handlar om igenkännande av syntaktisk (o)fullständighet.

\section{Tidigare forskning om elevers metasyntaktiska resonemang}

Forskning om elevers metalingvistiska aktiviteter har visat att elever har särskilt svårt för att artikulera sin metasyntaktiska förståelse (Myhill, 2012; Watson \& Newman, 2017). Detta kan delvis förklaras mot bakgrund av att resonemang om språkets strukturella egenskaper ofta kräver användning av grammatisk terminologi (t.ex. Hansson, 2009; Watson \& Newman, 2017). Forskning om elevers metalingvistiska resonemang om sina egna texter visar bland annat att explicit grammatiskt metaspråk är ett centralt verktyg för att kunna identifiera och förklara grammatiska strukturer (Watson \& Newman, 2017). Van Rijt et al.s (2019) interventionsstudie påvisar att elevers metalingvistiska resonemang är betydligt mer utvecklade efter explicit undervisning av grammatisk terminologi. Däremot kan ett för starkt fokus på grammatisk terminologi resultera i okritiska samtal, där eleverna endast hänvisar till memorerade begrepp (Fontich, 2014). Elevers användning av grammatisk terminologi behöver på så sätt inte bygga på kunskap och förståelse, och kan därmed snarare resultera $\mathrm{i}$ tomma ord. Grammatisk terminologi kan således fungera som ett verktyg i samtalen, men kan också utgöra ett hinder för att kritiskt utforska språk.

I flera studier har det emellertid framkommit att förståspråkselever i huvudsak inte använder sig av grammatisk terminologi när de resonerar om språkets struktur, utan de utgår primärt från semantiska associationer när grammatiska strukturer identifieras och förklaras, vilket kan försvåra möjlighet att se språkliga strukturer (t.ex. Boivin, 2018; Funke, 2018; Myhill, 2000; Watson \& Newman, 2017). I praktiken kan det exempelvis innebära att elevers sökande efter satsens verb resulterar i att verbala aspekter återfinns i andra satsdelar än predikatet (Myhill, 2000). Enligt van Rijt et al. (2019) tyder detta på att förstaspråkselever verkar vara mer bekväma med att prata om betydelser eftersom det är mer naturligt för dem och eftersom det generellt sett inte kräver explicit grammatisk terminologi. Vidare konstaterar van Rijt et al. (2019) 
att när eleverna utgår från semantik präglas resonemangen i högre utsträckning av intuition medan ett syntaktiskt fokus ofta innefattar resonemang av högre kvalitet, eftersom de i regel underbyggs av den explicita grammatikundervisningen. Fontich (2014) visar emellertid att om man i undervisning exempelvis fokuserar på satsdelars semantiska roller kan semantiska associationer fungera som ett stöd, vilket dessutom stimulerar en högre grad av engagemang bland eleverna. Beroende på utgångspunkt behöver således inte betydelse och struktur uppfattas som två separata perspektiv i grammatisk analys, utan kan förstås som ömsesidigt konstituerande.

Vidare är satsdelsfrågor, eller minnesregler, i syfte att identifiera grammatiska strukturer en strategi som elever förlitar sig på och de är även något som har präglat den dekontextualiserade, traditionella grammatikundervisningen i förstaspråksämnet (t.ex. Boivin, 2018; van Rijt et al., 2019). Det kan till exempel röra sig om att eleverna använder sig av vad-frågan (vad + predikat + subjekt) för att identifiera objektet i en sats (jfr Van Rijt et al., 2019). Att utgå från minnesregler i grammatikundervisningen har kritiserats eftersom de inte leder till reell språklig medvetenhet, då det inte stimulerar kritiskt tänkande och resulterar i att grammatisk analys behandlas som en gåta med endast en unik lösning (Berry, 2015; van Rijt \& Coppen, 2017). Vidare kan även poängteras att utgångspunkten i minnesregler dessutom ofta resulterar i att eleverna ger grammatiskt felaktiga svar (Brøseth \& Nygård, 2019). Van Rijt och Coppen (2017) menar att om minnesregler är den enda strategin som används i undervisningen, är det inte särskilt anmärkningsvärt att elever inte förstår vad som är ett objekt i en sats. Vidare har applicerandet av dem inte nödvändigtvis något värde för den grammatiska analysens kvalitet.

\section{Några grammatiska utgångspunkter}

För att förstå analysen av elevernas resonemang om syntaktisk (o)fullständighet i det valda textutdraget krävs en redogörelse för några grammatiska utgångspunkter. I denna artikel analyseras elevers resonemang om syntaktisk (o)fullständighet i ett skönlitterärt textutdrags meningar, vilka kan vara huvudsatsformade eller icke huvudsatsformade. De huvudsatsformande meningarna är grammatiskt självständiga och innehåller en huvudsats med subjekt och predikatsled inklusive dennas eventuella bisatser (jfr Hultman, 2003). De icke huvudsatsformade meningarna refererar i denna artikel till meningar som saknar subjekts- och/eller predikatsled. I Svenska Akademiens grammatik (Teleman et al., 1999) sägs följande: "En sats eller en fras som inte själv är led i en annan sats fungerar som en mening" (Vol 1, s. 53). För att underlätta resultatpresentationen i denna studie sammanfaller emellertid inte en mening med en syntaktisk mening, utan en mening är allt från stor bokstav till stort skiljetecken och den kan i sin tur vara huvudsatsformad eller icke huvudsatsformad.

I skriftspråk utgör huvudsatsformade meningar den språkliga normen, men avvikande strukturer kan förekomma. I skönlitterära texter är icke huvudsatsformade meningar särskilt vanliga av stilistiska skäl och de kan bland annat utgöras av preciserande eller förstärkande tillägg eller exempel till föregående mening (Lundin, 2004; 


\section{A. Strandberg E् O. Toropainen}

Schuster, 2006 ; Teleman et al., 1999). Dessa preciseringar ger ytterligare information till en föregående sats eller till innehållet $i$ en föregående mening. I skönlitterära texter kan icke huvudsatsformade meningar exempelvis skapa en intensiv emfas åt ett enskilt led (Schuster, 2006), som i följande exempel: Hon köpte en Volvo. En röd, äldre modell. I exemplet följs den huvudsatsformade meningen av en icke satsformad mening i form av en nominalfras som specificerar remat [Volvo], från föregående sats. ${ }^{1}$ Strukturellt kan dylika meningar variera. De kan exempelvis vara nominalfraser eller bisatser.

Det skönlitterära textutdraget som är aktuellt i föreliggande studie härstammar från Stina Jacksons roman Silvervägen och innehåller en rad icke huvudsatsformade meningar. Dessa är markerade med [IHM] i följande utdrag.

Meja låg med händerna över magen och försökte att inte lyssna efter ljuden. Hungern som skrek under hennes fingrar och sedan det andra [IHM]. De äckliga ljuden som trängde sig upp genom de glesa golvplankorna [IHM]. Siljes flämtande andhämtning och sedan hans, den nye mannens [IHM]. Gnisslandet från sängstolparna och så hunden som började skälla [IHM]. Hon hörde hur mannen röt åt den att gå och lägga sig. (Jackson, 2018, s. 13-14)

Som utdraget visar inleder författaren stycket med en mening som består av två samordnade huvudsatser med ett gemensamt subjekt. Den inledande meningen efterföljs sedan av fyra icke huvudsatsformade meningar av vilka den första, andra och fjärde innehåller en fullständig relativ bisats som fungerar som ett efterställt satsattribut och bildar således en utbyggd nominalfras som i sin tur fungerar som satsens subjekt. Däremot saknar satsen i meningen ett predikatsled. Som det framgår av excerpten kan icke huvudsatsformade meningar även inkludera adverb- och nominalfraser (och sedan det andra; och sedan hans, den nye mannens). Samtliga IHM fungerar som specificeringar av remat av den inledande meningen: remat i den första meningen [juden] specificeras således av alla efterföljande icke huvudsatsformade meningar. Dessa meningar kan med andra ord förstås som tillhörande led till den inledande meningen (ett kolon efter ljuden skulle exempelvis synliggöra detta).

\section{Material och metod}

Materialet är som tidigare nämnt hämtat från den första iterationen i ett designbaserat forskningsprojekt där grammatikundervisningen kopplas samman till arbete med spänningsromanen Silvervägen. Det var de deltagande lärarna som valde romanen mot bakgrund av att det var en roman som de hade arbetat med tidigare och som de ansåg fungerade väl i kurserna. I instruktionerna som eleverna tillhandahölls under iscensättningen av övningen framgick det att de först och främst skulle läsa textutdraget högt för varandra för att därefter identifiera syntaktisk (o)fullständighet i meningarna. Sedan skulle eleverna även testa att skriva om de

\footnotetext{
${ }^{1}$ I ett påstående är remat det nya och intressanta, det som motiverar att påstående görs. Temat står vanligen i satsens början, och remat i dess slut (Teleman et al., 1999).
} 
icke huvudsatsformade meningarna till huvudsatsformade för att därefter jämföra och diskutera vilken betydelse och effekt författarens grammatiska val hade i den kommunikativa kontexten. I föreliggande artikel är fokus emellertid enbart på elevernas metasyntaktiska resonemang. Övningen föregicks av en explicit genomgång av fullständiga och ofullständiga satser och vad som kännetecknar dem samt hur detta kan återspeglas i skönlitteratur. Undervisningen behandlade exempelvis skillnaden mellan mening och sats samt subjekts- och predikatsled. Syftet med övningen var att uppmärksamma eleverna på dels språkliga strukturer och vad som konstituerar syntaktisk (o)fullständighet, dels hur författare kan utmana språkliga konventioner för en stilistisk verkan. Eleverna delades in i grupper av de lärare som deltar i det aktuella designbaserade forskningsprojektet. Samtalen filmades med en iPad utan någon närvarande observatör.

Det empiriska material som ligger till grund för artikeln utgörs av tre videoinspelade gruppsamtal (se Tabell 1). iPad-kameran har stått på under hela övningen, från det att eleverna satte sig i grupprummet tills de var färdiga med övningen. Endast det som rör övningen har transkriberats medan samtal om annat har utelämnats. Ibland förekommer längre tystnader då eleverna antingen läser, funderar eller skriver ner det som de har kommit fram till. Gruppsamtalens längd kan därför inte relateras till antal yttranden. Eleverna är 15-17 år och har själva valt de fingerade namn som återges i artikeln. Samtliga deltagare har lämnat skriftligt samtycke till att delta i studien.

Tabell 1. Videoinspelade gruppsamtal

\begin{tabular}{cccc}
\hline Grupp & Längd (mm:ss) & Antal elever & Antal yttranden \\
\hline 1 & $25: 59$ & 4 & 447 \\
2 & $18: 48$ & 4 & 217 \\
3 & $17: 27$ & 4 & 218 \\
\hline
\end{tabular}

De inspelade gruppsamtalen har transkriberats verbatim med avseende på läsbarhet. Eftersom artikeln fokuserar på vad eleverna säger och inte hur interaktionen aktualiseras har elevernas yttranden utformats som grammatiska meningar där inga hänsyn har tagits till pauser, överlappande tal och dylikt. Videoinspelningen har därför enbart fungerat som ett praktiskt stöd vid transkriptionen för att exempelvis kunna avgöra vem i gruppen som talar.

\section{Kvalitativ innehållsanalys}

För att analysera på vilka sätt eleverna resonerar om textutdragets syntaktiska (o)fullständighet tillämpades kvalitativ induktiv innehållsanalys, eftersom det är en lämplig analysmetod för att tolka och beskriva verbala data (Hsieh \& Shannon, 2005; Schreier, 2012). Metoden kännetecknas som systematisk och flexibel och dess närhet till empirin tillåter kategoriformationen att växa fram ur elevernas yttranden (Schreier, 2012). 


\section{A. Strandberg E् O. Toropainen}

Initialt lästes samtliga transkriberade elevgruppssamtal flera gånger av förstaförfattaren för att skapa en helhetsförståelse. Sedan kodades materialet induktivt men fokuserat i NVivo (Bazeley \& Jackson, 2013), där endast aspekter av datamaterialet som var relevant för forskningsfrågan beaktades (jfr Hsieh \& Shannon, 2005). Fokus var således resonemang som, latent eller manifest, tangerade meningarnas grammatiska struktur. Med utgångspunkt i forskningsfrågan grupperades koderna därefter till kategorier. Alla kodade yttranden inom en och samma kategori granskades för att identifiera kärnan inom kategorin, som sedan namngavs och definierades baserat på de meningsbärande enheter som grupperats samman inom kategorin (se Tabell 2). Resultatet i form av kategoripresentationen från innehållsanalysen är därför baserat på elevernas yttranden och därmed grundade i empirin. Kategorierna kontrasterades sedan gentemot varandra för att synliggöra eventuella relationer mellan respektive kategori.

Tabell 2. Exempel på induktiv kategoriformation

\begin{tabular}{|c|c|c|}
\hline Dataexcerpt & Beskrivning & Kategori \\
\hline det är ju någonting som gör något mot någon & \multirow{3}{*}{$\begin{array}{l}\text { Minnesregler styr resonemangen, } \\
\text { i form av exempelvis förenklade } \\
\text { satsdelsfrågor där ett krav på subjekt } \\
\text { och predikat framträder. Meningarna } \\
\text { isoleras från varandra. }\end{array}$} & \multirow[t]{3}{*}{ Minnesregel } \\
\hline $\begin{array}{l}\text { men det står ju Meja låg med händerna på magen, } \\
\text { vad gjorde hon? Låg med händerna på magen }\end{array}$ & & \\
\hline $\begin{array}{l}\text { det handlar om Meja det beskriver vad hon gör } \\
\text { och allt sånt där som en mening ska innehålla }\end{array}$ & & \\
\hline
\end{tabular}

Slutligen analyserades och kodades allt datamaterial på nytt med utgångspunkt $\mathrm{i}$ de induktiva kategoriformationerna som med tillhörande beskrivningar fungerade som utvecklad kodningsmanual (jfr Schreier, 2012). I detta skede synliggjordes även huruvida de utelämnade yttrandena inte kunde relateras till forskningsfrågan och därmed om all relevant information hade kategoriserats. Kodningen kontrollerades vidare av andraförfattaren och en dialog kring svårkategoriserade yttranden fördes för att nå samsyn.

Kodade yttranden kan variera i längd: en lång sekvens av ett resonemang kan synliggöra en och samma kategori men också skifta mellan kategorier. På grund av resonemangens heterogena karaktär kvantifieras inte kategorierna, utan resultatpresentationen är kvalitativ (jfr Schreier, 2014). För att förstå elevernas resonemang isoleras inte deras yttranden i resultatpresentationen, utan sekvenser av samtalen presenteras för att knyta samman yttranden till den kontext de är sprungna ur. De resonemang av en återgiven samtalssekvens som representerar den adresserade kategorin är därför markerade i fetstil. På så sätt kan en kontextuell förståelse för elevernas resonemang även ges.

\section{Resultat}

Den induktiva innehållsanalysen av elevsamtalen resulterade i tre kategorier som representerar elevernas varierade sätt att resonera om den syntaktiska (o)fullständigheten 
i textutdraget. Elevernas resonemang kodades till följande kategorier: (i) minnesregel, (ii) innehåll och (iii) texthelhet. I sina resonemang utgår eleverna inom respektive kategori från såväl språklig intuition som grammatisk terminologi. Detta är emellertid inte fokus i resultatredovisningen, utan snarare resonemangens övergripande kännetecken inom respektive kategori. Analysen exemplifieras genom utvalda excerpt för att illustrera kategorierna och elevgruppernas resonemang presenteras kategori för kategori. Eftersom alla grupper inleder med resonemang som stödjs av minnesregeln (kategori i) och eftersom två av grupperna avslutar i texthelhet (kategori iii) speglar resultatredovisningen även en kronologi i syfte att synliggöra när respektive kategori aktualiseras i samtalen. Vid varje excerpt skrivs den adresserade elevgruppen fram i excerptrubriken med tillhörande numrering för yttrandena, och de yttranden som är centrala för kategorin är markerade i fetstil. När eleverna läser upp delar av textutdraget är yttrandena kursiverade. Hänvisningar till textutdragets meningar återges i hakparentes.

\section{Minnesregel}

Den första kategorin är förknippad med den traditionella skolgrammatiken där minnesregler, i form av exempelvis förenklade satsdelsfrågor, styr resonemangen. Eleverna utgår från att syntaktisk fullständighet konkretiseras genom existerande subjekt och predikat (någonting som gör något mot någon). När eleverna utgår från minnesregeln förstår de således subjekt som någon som utför en handling, och predikat som ord som beskriver en handling. Centralt för denna kategori är även att eleverna resonerar om meningarna i textutdraget isolerade från varandra. Minnesregeln som eleverna använder kan uttryckas på olika sätt, men kontentan är det implicita kravet på aktör och handling för att bilda syntaktisk fullständighet. I grupp 1 (Excerpt 1) används minnesregeln när eleverna diskuterar textutdragets inledande mening [Meja låg med händerna på magen och försökte att inte lyssna efter ljuden].

\section{Excerpt 1. Grupp 1 [9-16]}

Joakim ja och då tror jag att den första är fullständig

Kent ja, första är fullständig. Jag skriver F på den

Ruben fast ljuden, vilka ljud liksom?

Joakim men det står ju Meja låg med händerna på magen, vad gjorde hon? Låg med händerna på magen

Kent vänta

Ruben ja Meja är det

Thomas och låg

Joakim Meja... det behövs inte mer än så. Vad gjorde hon? Hon låg. Hon behöver inte mer än så

Genom att utgå från en minnesregel i form av en satsdelsfråga för predikat (vad gjorde hon?) argumenterar eleverna i Excerpt 1 för att den inledande satsen $i$ den första meningen är fullständig: det är någon (Meja) som genomför en handling (låg). Vid resonemang om den inledande satsen fungerar applicerandet av 


\title{
A. Strandberg E् O. Toropainen
}

minnesregeln och eleverna godkänner motiveringen. Senare när detta kommer att bli utgångspunkten för de icke huvudsatsformande meningar tenderar eleverna att låsa sig vid förståelsen av subjekt och predikat som aktör och handling och eleverna förbiser den övergripande syntaktiska strukturen i meningen. Eleverna har svårt att dra slutsatser med hjälp av minnesregeln när de resonerar om textutdragets andra mening [Hungern som skrek under hennes fingrar och sedan det andra]. I Excerpt 2 följer ett exempel på detta.

\section{Excerpt 2. Grupp 1 [34-37]}

Joakim men jag tror inte tvåan... den är väl ofullständig?

Kent hungern som skrek under hennes fingrar och sedan det andra

Ruben ja den är ju ofullständig

Thomas nej, för hungern är det och sen skrek

Joakim och Ruben anser att denna icke huvudsatsformade mening är ofullständig medan Thomas hävdar att den är fullständig eftersom hungern skriker. Thomas söker efter potentiella ord som fungerar som aktör och handling, vilket skapar motsättningar när meningen utgörs av en nominalfras med efterföljande satsattribut som fungerar som satsens subjekt. Resonemanget belyser hur den tidigare förståelsen av subjekt och predikat som aktör och handling kan försvåra möjligheten att se satsdelarnas grammatiska funktion då predikatsledet i den relativa bisatsen förstås som ett predikatsled för huvudsatsen.

Precis som grupp 1 inleder grupp 2 samtalet med resonemang som stödjs av en minnesregel. Efter att elevgruppen har identifierat syntaktisk fullständighet $\mathrm{i}$ den första meningen, kräver den andra resonemang där eleverna måste motivera sin ståndpunkt eftersom de först inte är överens, och det är nu minnesregeln aktualiseras.

\section{Excerpt 3. Grupp 2 [25-29]}

\author{
Anna okej, den andra är... ofullständig. Ja \\ George hungern som skrek \\ George det känns lite sådär \\ Isabelle alltså jag tänkte den var fullständig \\ George ja, för jag känner att det är ju någonting som gör något mot någon
}

Anna konstaterar att meningen är syntaktiskt ofullständig, medan George och Isabelle anser att den är fullständig. I likhet med grupp 1 vänder sig George till en form av minnesregel där subjekt och predikat realiseras (någon som gör något), vilket innebär att den i sammanhanget tolkas som fullständig. Att denna passage visar sig svår för eleverna kan förklaras mot bakgrund av att det handlar om en fristående nominalfras med vissa inbyggda satsegenskaper (så som verbet skrek). När minnesregeln används i grupp 3 (Excerpt 4) är det den första satsen i den första meningen som leder in eleverna på kravet på subjekt och predikat, vilket precis som för föregående grupper skapar motsättningar när de sedan resonerar om den efterföljande meningen. 


\author{
Excerpt 4. Grupp 3 [21-31] \\ César det låter som en fullständig mening \\ Lars ja, asså det är liksom, det handlar om Meja det beskriver vad hon gör \\ och allt sånt där som en mening ska innehålla \\ Pascal det borde ju vara, jo \\ Lars ja. Hungern som skrek under hennes fingrar och sedan det andra. Och det är \\ en ofullständig mening \\ Pascal är det inte en fullständig? Det beskriver ju att det är hungern som \\ skriker, även om det typ är konstigt \\ César man vet att det är hon, man vet hungern, att det är den som skriker \\ Lars eller ja... \\ Pascal det är hungern som skriker och beskrivs hur, ja inte hur men, jo \\ typ. Hur hungern skriker \\ César så vi säger fullständig på den? \\ Pascal jag vet inte jag skulle tänka det \\ Lars alltså jag vet inte... det låter lite konstigt
}

Vid resonemang om den inledande satsen i meningen är eleverna överens om att den är syntaktiskt fullständig. Lars försöker sätta ord på de satsdelar som krävs för att en sats ska vara fullständig, vilket aktualiserar minnesregeln (det handlar om ett subjekt, Meja, och det innehåller en handling, vad hon gör). När eleverna följaktligen resonerar om den andra meningen vållar utgångspunkten i minnesregeln problem, precis som för grupp 1 och 2. 'Hungern' förstås av César och Pascal korrekt som ett subjekt medan verbet (skrek) i den efterföljande bisatsen uttrycker en handling för huvudsatsens subjekt, vilket i kontrast till föregående motivering skapar förvirring i gruppen. Lars uttrycker emellertid att det är något som skaver, låter lite konstigt, eftersom hans språkliga intuition talar emot minnesregeln. Minnesregeln kan visserligen aktualisera satsdelarnas grammatiska funktion, men eftersom eleverna realiserar subjekt och predikat på betydelsemässig basis försvårar minnesregeln igenkännandet av den icke huvudsatsformade meningen och blir otillräcklig för att nå konsensus och eleverna vänder sig i fortsättningen till andra tillvägagångssätt.

\title{
Innehåll
}

I den andra kategorin, innehåll, isoleras även de icke huvudsatsformade meningarna, men här är fokus på meningars och ords enskilda betydelser. Om en mening är huvudsatsformad avgörs av huruvida eleverna förstår dess innehåll, vilket kan innebära att om något är öppet för tolkning kan det resultera i att eleverna utgår från att en sats i meningen saknar en obligatorisk satsdel. Satsens syntaktiska fullständighet avgörs därför av huruvida den uttrycker en, enligt eleverna, fullständig tanke. Denna utgångspunkt tenderar att låsa eleverna vid betydelser och leder in dem på resonemang om enskilda ord, vilket gör att den syntaktiska strukturen hamnar i skymundan. I grupp 1 är denna kategori särskilt framträdande då gruppen hädanefter primärt fokuserar på meningars och ords enskilda betydelser, vilket innebär att de har svårt att känna igen de icke huvudsatsformade meningarna. 


\title{
A. Strandberg E् O. Toropainen
}

Betydelsetolkningar blir resonemangens kärna och syntaktisk fullständighet avgörs på basen av huruvida eleverna förstår innehållet isolerat från sitt textuella sammanhang. I Excerpt 5 följer exempel på detta när gruppen resonerar om den femte meningen.

\section{Excerpt 5. Grupp 1 [94-98]}

\author{
Ruben okej. Gnisslandet från sängstolparna och så hunden som började skälla. \\ Kent den här är ju ofullständig \\ Thomas den är fullständig \\ Ruben jo \\ Thomas från sängstolparna, så den förklarar
}

I det avslutande citatet i Excerpt 5 konstaterar Thomas att den icke huvudsatsformade meningen är fullständig eftersom den förklarar någonting. Fullständighet avgörs därför av huruvida den inrymmer en klargörande beskrivning. Långt senare i samtalet är fokus visserligen fortfarande meningarnas enskilda betydelser, men i följande resonemang (Excerpt 6) resulterar utgångspunkten i att eleverna lyckas känna igen den syntaktiska ofullständigheten [De äckliga ljuden som trängde sig upp genom de glesa golvplankorna].

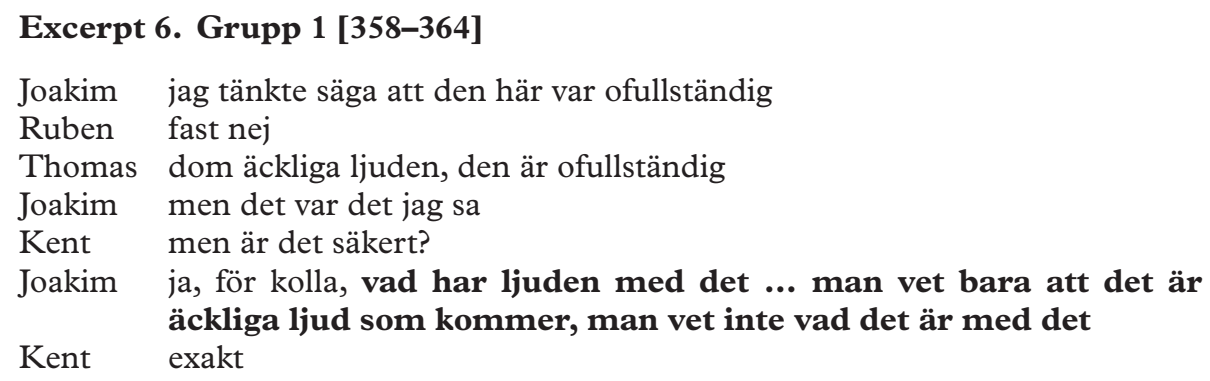

Gruppen tycks ense trots att motiveringen är syntaktiskt otillräcklig, eftersom Joakim utgår från betydelsemässiga tolkningar i sitt resonemang. Meningen tolkas som innehållsmässigt otillräcklig och därför menar Joakim att den karaktäriseras av syntaktisk ofullständighet. Eleverna kommer emellertid aldrig fram till vilka satsdelar det är som saknas. Elevgruppens betydelsemässiga och isolerade fokus på varje enskild mening innebär vidare att samtalet präglas av resonemang som rör betydelsetolkningar av enskilda ord och meningar som sedan aldrig följs upp, och eleverna i grupp 1 når aldrig konsensus om vilka meningar som är syntaktiskt ofullständiga i textutdraget.

Grupp 3 utgår även de från innehållet i delar av sina resonemang. Efter att minnesregeln bedömts som otillräcklig övergår gruppen visserligen till att koppla samman de icke huvudsatsformade meningarna och den tredje kategorin, texthelhet, aktualiseras (se nästa avsnitt), men därefter väljer gruppen att återigen isolera meningarna när även de resonerar om den tredje meningen och dess betydelse. I Excerpt 7 blir den andra kategorin aktuell för gruppen då de anser att de utelämnade satsdelarna inte påverkar innehållet i tillräcklig utsträckning. 


\section{Excerpt 7. Grupp 3 [55-60]}

César den tredje då. De äckliga ljuden som trängde sig upp genom de glesa golvplankorna.

Lars så ofullständig

César då vet man ju inte vilka ljud det är

Pascal tänker, vad är det vi måste lägga till i så fall. För att vi skulle få en fullständig... om vi tar typ 'det var dom äckliga ljuden som trängde sig upp genom dom glesa golvplankorna' blir det inte heller så

Lars nä jättemycket annorlunda

César man vet fortfarande inte vilka ljud det är

Meningen urskiljs som syntaktiskt ofullständig av César eftersom man inte vet vilka ljud det rör sig om. Pascal och César uttrycker att det potentiellt utelämnade 'det' och 'var' ändå inte löser problemet, eftersom eleverna fortfarande inte vet vilka ljud det rör sig om. Detta kan tolkas mot bakgrund av att 'det var' primärt har ett syntaktiskt syfte, utan egentlig betydelse i sig själv, vilket förklarar elevernas förvirring när de förlitar sig på betydelsen som avgörande faktor för syntaktisk fullständighet. Resonemang rörande innehåll återfinns därmed här genom att eleverna utgår från att inget ska vara öppet för tolkning. Excerpt 7 kan tolkas så att betydelsemässiga resonemang blir otillräckliga i de fall där meningarna isoleras från varandra.

\section{Texthelhet}

Slutligen följer den tredje kategorin, texthelhet, där utgångspunkten för resonemangen är att samtliga meningar analyseras i relation till varandra, såväl syntaktiskt som semantiskt. När den textuella kontexten blir utgångspunkt i resonemangen aktualiseras meningarnas grammatiska struktur eftersom de utelämnade satsdelarna blir i fokus (vad, i sammanhanget, är det som strukturellt och semantiskt saknas). Resonemangen stödjs dock primärt av de icke huvudsatsformade meningarnas semantiska samband till kringliggande meningar där eleverna exempelvis utgår från att de kan precisera remat från föregående sats. I dessa resonemang knyter eleverna således an den icke huvudsatsformade meningen till föregående för att kunna identifiera de potentiellt saknade satsdelarna. Detta innebär följaktligen att kategorin inrymmer resonemang rörande redundans, eftersom de identifierade utelämnade satsdelarna i sammanhanget bedöms som självklara.

Eftersom isolerandet av meningarna visar sig otillräckligt i resonemangen rörande textutdragets första icke huvudsatsformade mening [Hungern som skrek under hennes fingrar och sedan det andra], väljer grupp 2 och 3 att knyta an meningarna till varandra. Eleverna kontextualiserar nu meningen och de utelämnande satsdelarna förstås i relation till kringliggande meningar, vilket visar sig avgörande för elevernas resonemang om textutdragets syntaktiska (o)fullständighet och därmed igenkännandet av den. Excerpt 8 visar hur tidigare resonemang baserat på minnesregeln (se Excerpt 4) övergår till att en gruppdeltagare fokuserar på det potentiella utelämnandet, vilket följs av resonemang som stödjs av meningens textuella anknytning. 
Excerpt 8. Grupp 3 [35-41]
Alicia det kan ju, man kan ju skriva säkert att 'det var hungern som skrek'... men jag vet inte
Lars jag tror att man ska börja med 'det var'. Men jag vet inte
César ja
Lars för att alltså det beskriver ju ändå, hon försökte att inte lyssna efter ljuden. Och det här liksom beskriver ju vilka ljud som det var, men då måste man inleda med ett 'det var'
Alicia mm
Lars alltså, för det var hungern som var ljuden som hon hörde. Eller det Pascal ja var hungern som skrek och det andra som var ljuden som hon hörde

Genom att urskilja utelämnandet i relation till föregående huvudsatsformade mening föreslår Alicia att det är 'det var' som saknas (formellt subjekt och ett finit verb). Lars håller med om detta och förklarar det genom att koppla samman meningarna: ljuden (remat) i den första meningen preciseras närmare i efterföljande icke huvudsatsformade meningar. Eleverna saknar det explicita grammatiska metaspråket för att sätta ord på intuitionen (så som exempelvis formellt och egentligt subjekt samt predikatsled) och vänder sig till meningarnas semantiska samband. Resonemangen om strukturen stödjs således av meningens textuella anknytning och eleverna når konsensus.

I likhet med grupp 3 motiverade grupp 2 igenkännandet av syntaktisk (o)fullständighet i samtliga icke huvudsatsformade meningar i textutdraget baserat på deras textuella anknytning. I Excerpt 9 följer ett exempel på hur den tredje kategorin återfinns i gruppens resonemang.

\section{Excerpt 9. Grupp 2 [98-101]}

Isabelle ja, men som du George sa innan, att här, först säger hon så här 'Meja låg med händerna över magen' och sen är det alla dom här ljuden som liksom beskriver som första, ja men det här, ljuden i första meningen

Julia alltså vi har ju fått all information från den första meningen

Anna ja exakt

Julia sen krävs det ju inte att vi skriver och upprepar Meja gjorde, hon såg, hon tänkte, utan det krävs ju bara dom här ofullständiga meningarna

Eleverna hävdar att de icke huvudsatsformade meningarna preciserar ljuden i den inledande meningen. Eleverna konstaterar att de utelämnade satsdelarna i sammanhanget, vilket enligt eleverna är subjekt och predikat, är redundanta, eftersom de inte bidrar med något till betydelsen utöver vad som redan framgår ur återstoden av texten. Elevernas resonemang om utelämnandet synliggör att de förutsätter att det finns, eller åtminstone har funnits, en föreställning om en språklig helhet och att den avgörs av meningarnas textuella anknytning. I Excerpt 10 återvänder grupp 3 till huruvida det blir någon skillnad i betydelse när de utelämnade satsdelarna läggs till. Eleverna resonerar då, i likhet med grupp 2 (Excerpt 9), om att de utelämnade satsdelarna i 
relation till textutdraget i sin helhet inte har någon betydelsebärande funktion vilket legitimerar den syntaktiska ofullständigheten i textutdraget.

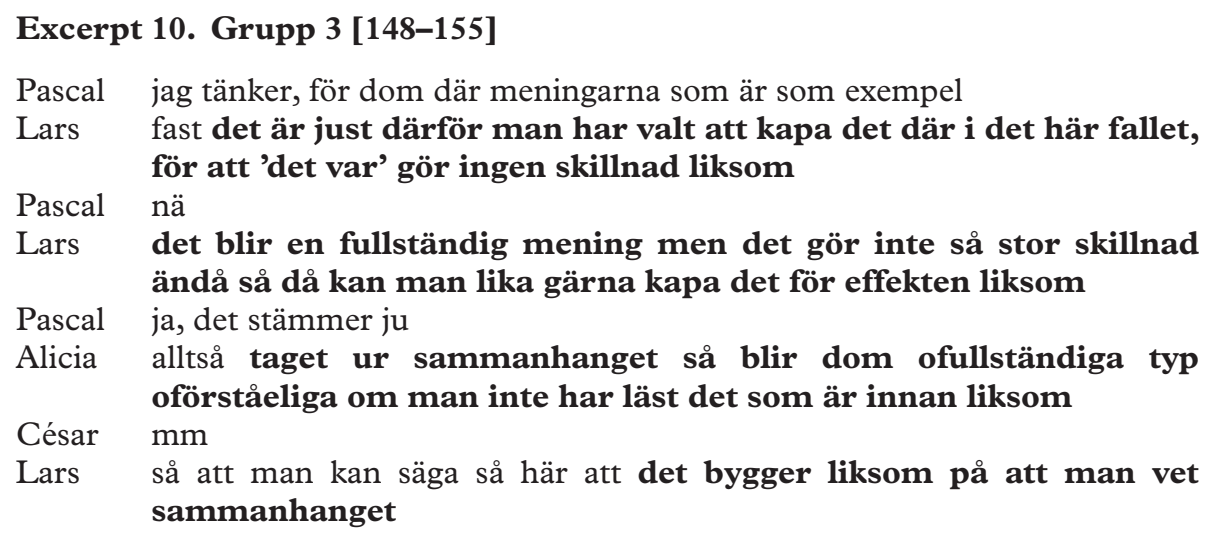

Grupp 3 kommer även de fram till att de icke huvudsatsformade meningarna är beroende av den textuella kontexten för att bli förstådda. Det är genom sammanhanget som eleverna kan igenkänna utelämnandet och därmed även den syntaktiska (o)fullständigheten.

I Excerpt 11 avrundar grupp 2 samtalet med att återvända till de utelämnade satsdelarnas textuella anknytning, då de resonerar om samtliga icke huvudsatsformade meningar och deras samband till den första meningen.

Excerpt 11. Grupp 2 [211-214]

Julia men alltså första meningen börjar ju liksom med att beskriva, och sen kommer alla dom här ljuden och sista meningen, den stänger som igen. Alltså liksom så här avslutar så här som...

Anna $\mathrm{mm}$

Julia dom fullständiga är ju, eller dom ofullständiga är ju väldigt beroende av dom fullständiga för att förstå

Anna ja, precis. Man använder ju, alltså ifall en mening, alltså en ofullständig mening saknar ett predikat så använder den ju predikatet från den förra meningen, som var lyssnar. Och ifall den saknar subjekt så använder den ju subjektet från den förra meningen. Typ Meja gick i skogen... och såg en varg, typ, då vet man ju liksom att det var Meja som såg en varg i skogen för det är inget annat subjekt, så ja

I Excerpt 11 är tolkningen av meningarnas innehåll centralt, men eleverna resonerar om dem i relation till textutdraget i sin helhet. De icke huvudsatsformade meningarna exemplifierar de ljud som beskrivs i den första meningen, och på så sätt kopplar eleverna samman meningarna. Julia lyfter sedan att den sista meningen, som de identifierat som syntaktiskt fullständig, fungerar som en avslutning då den enligt eleverna markerar att preciseringen av ljuden är fullbordad. Meningarnas textuella anknytning förklaras ytterligare med grammatisk terminologi av Anna i det sista yttrandet där hon konstaterar att utelämnandet innebär att subjekt eller predikat från föregående 


\section{A. Strandberg E् O. Toropainen}

huvudsatsformade mening återanvänds latent i efterföljande meningar. Det är med utgångspunkt $i$ texthelheten som eleverna kan igenkänna den syntaktiska (o)fullständigheten, men framför allt tillstå med en enligt gruppen bärande förklaring till varför det förhåller sig så.

\section{Diskussion}

Föreliggande artikel ämnade bidra med ökad kunskap om elevers resonemang om syntaktisk (o)fullständighet inom ramen för en kontextualiserad grammatikundervisning. Kontextualiserad grammatikundervisning utgår bland annat från autentiska texter och i denna studie valdes en skönlitterär text som inramning för autentiskt språkbruk eftersom syntaktisk (o)fullständighet där är särskilt utmärkande. Den induktiva innehållsanalysen av tre elevgruppers metalingvistiska aktiviteter resulterade $i$ tre kategorier som representerar elevernas varierade sätt att resonera om syntaktisk (o)fullständighet i textutdraget. Dessa kategorier är: minnesregel, innehåll och texthelhet. Samtliga tre elevgrupper inleder sina resonemang med att tillämpa en minnesregel för obligatoriska satsdelar i textutdragets meningar med avsikt att upptäcka och förklara den syntaktiska (o)fullständigheten. Vid de huvudsatsformade meningarna fungerar applicerandet av minnesregeln medan den blir otillräcklig vid de icke huvudsatsformade meningarna då eleverna exempelvis tolkar predikatet i den relativa bisatsen som ett predikatsled för huvudsatsen (jfr Myhill, 2000). Kunskapen om obligatoriska satsdelar tillämpas således på betydelsemässiga grunder i elevgrupperna då applicerandet av minnesregeln resulterar i att enskilda ord som kan uttrycka en handling förstås som predikatsled (jfr Boivin, 2018; Funke, 2018; Myhill, 2000). Resonemangen visar att minnesregler såväl kan försvåra som stödja resonemanget om syntaktisk (o)fullständighet (jfr Berry, 2015, van Rijt et al., 2019). Det mekaniska tillvägagångssätt som minnesregler innebär kan fungera när tillrättalagda huvudsatser analyseras, eller när det gäller att identifiera enskilda satsdelar utan kunskap om dess grammatiska funktion i satsen, men när autentiska texter innehållande syntaktiskt (o)fullständighet är utgångspunkt vållar emellertid applicerandet av minnesregeln problem. Vidare kan noteras att minnesregler inte var ett inslag i den explicita undervisningen som föregick övningen, vilket är anmärkningsvärt i sammanhanget.

I den andra kategorin, innehåll, utgör elevernas förståelse av meningarnas innehåll ett krav för syntaktisk fullständighet, vilket leder in eleverna på resonemang om enskilda ord och deras betydelser och kategorin blir därmed ett problematiskt tillvägagångsätt för att igenkänna den syntaktiska (o)fullständigheten. Att eleverna förlitar sig på betydelser kan, precis som van Rijt et al. (2019) konstaterar, vara för att eleverna är mer vana vid att diskutera betydelser än strukturer och vänder sig därför till tolkningar av innehållet där intuitioner blir framträdande. Som analysen visar kan elevernas fokus på enskilda ord och meningars betydelser försvåra och "låsa in" dem i resonemangen, och strukturen hamnar i skymundan. Det betyder inte att betydelse 
och innehåll är oviktiga, men för att lyckas i syntaktisk analys bör syntaxen initialt separeras från semantik.

Vidare visar den tredje kategorin, texthelhet, den kontextualiserade grammatikundervisningens möjligheter i processen att såväl urskilja som förklara den potentiella (o)fullständigheten i meningar. Eleverna förlitar sig visserligen först på den mekaniska minnesregeln men när den blir otillräcklig för att nå konsensus väljer två elevgrupper att utnyttja textutdraget i sin helhet i resonemangen. Genom att koppla samman meningarna kan eleverna upptäcka och förklara den syntaktiska (o)fullständigheten och resonemangen kan då även stödjas av argument rörande redundans, vilket utgör ett centralt inslag i förståelsen av meningsfragment (Lundin, 2004). Mot bakgrund av den explicita grammatikundervisningen som eleverna deltagit i innan övningen är dock resonemang rörande huvudsatser och dess faktiska beståndsdelar relativt frånvarande. Trots att eleverna utnyttjar den textuella anknytningen hade resonemangen blivit än mer fördjupade om tydligare kopplingar till exempelvis subjekt- och predikatsled hade gjorts. Resonemangen inom den tredje kategorin synliggör å andra sidan ett mer nyanserat förhållande mellan betydelse och struktur eftersom kategorin visar att det finns betydelseaspekter som är grammatiskt relevanta om textutdraget utnyttjas i sin helhet. I den tredje kategorin fungerar nämligen innehållet som meningarna tillsammans bildar som ett stöd för eleverna i resonemangen (jfr Fontich, 2014). Tanken om att de icke huvudsatsformade meningarna fungerar som preciserande tillägg till remat i den första huvudsatsformade meningen använder eleverna som grund för att förklara det strukturella utelämnandet (jfr Lundin 2004; Schuster, 2006). I likhet med Watson och Newmans (2017) resultat visar sig grammatisk terminologi delvis vara ett hjälpmedel för att förklara avsaknaden av en obligatorisk satsdel (Excerpt 11), men samtidigt är det primärt inte det som grupperna stödjer sig på för att förklara textutdragets syntaktiska (o)fullständighet. Den tredje kategorin visar snarare att eleverna utnyttjar meningarnas textuella anknytning som ett tillvägagångssätt i resonemangen.

Studiens resultat visar sammantaget att de två första tillvägagångssätten försvårar möjligheten att igenkänna och förklara den syntaktiska (o)fullständigheten i textutdraget eftersom betydelser sätts i förgrunden. Infallsvinklarna som de olika kategorierna innebär kan visserligen kombineras, vilket skapar förutsättningar för fördjupningar i resonemangen. Samtidigt visar Boivin (2018) att det finns en didaktisk utmaning $\mathrm{i}$ att förstaspråkselever tenderar att fastna i betydelser och mekaniska minnesregler, då det kan försvåra möjligheten att lyfta blicken och se strukturer. Att utforska språket ur ett brett perspektiv, där struktur, betydelse och kontext tas in (Gombert, 1992; Myhill et al., 2013), är visserligen betydelsefullt men kan också skapa förvirring när skiften mellan de olika perspektiven krävs. Som resonemangen visar är skiftet från att se betydelse till att se struktur utmanande för elever då det kräver olika sätt att läsa (jfr Camps \& Fontich, 2019). Eftersom minnesregler är vanligt förekommande är det viktigt att lärare är medvetna om deras begränsningar när elever ska närma sig satsdelars grammatiska funktion i texter där avvikande strukturer 


\section{A. Strandberg E् O. Toropainen}

kan förekomma. Det är viktigt att notera att elever behöver få möjlighet att träna på och bli vana vid de olika läsningar som krävs för att resonera om språkets struktur, betydelse och kontext. Även om ett blockmoment av explicit grammatikundervisning visserligen kan vara motiverat för att eleverna ska få vissa grundkunskaper i grammatik bör den inte stanna där (Watson, 2012), utan i stället kontinuerligt och gradvis kontextualiseras till samtliga moment i förstaspråksundervisningen (Kabel \& Bjerre, 2020). Detta erbjuder möjligheter för en inkluderande undervisning kring språkets olika nivåer och eleverna får succesivt träna upp förmågan att växelverka mellan betydelse och struktur, för att i sin tur utveckla en förståelse för grammatiska val som betydelseskapande val (Myhill et al., 2013).

Att identifiera och förklara grammatiska strukturer är utmanade för elever (t.ex. Boivin, 2018; Watson \& Newman, 2017), men den här studien visar att när ett skönlitterärt textutdrag innehållande syntaktisk (o)fullständighet blir utgångspunkt kan eleverna utgå från andra strategier än enbart minnesregler för att förklara utelämnandet. Textutdragets fragmentariska skrivning kan bidra till att eleverna noterar språkets strukturella aspekter för att söka en förklaring till den syntaktiska (o)fullständigheten bortom den enskilda meningen (jfr Schuster, 2006). Eleverna bjuds således in till att utforska strukturer när syntaxens principer inte förverkligas i meningen, så som är fallet i textutdraget eleverna analyserar. Resultatet antyder delvis att när eleverna använder sig av texthelheten (kategori iii) kan de växla mellan såväl semantiska som syntaktiska perspektiv, vilket innebär att elevernas repertoar nödvändigtvis inte är begränsad till ett metalingvistiskt perspektiv som är separat kopplat till syntax eller semantik (jfr Fontich, 2014), utan perspektiven är snarare sammanflätade. Textutdraget skapar på så sätt en spänning mellan å ena sidan sats, mening och text, å andra semantik och syntax. Skönlitterära texters didaktiska potential för liknande växelverkan hade med fördel kunnat undersökas närmare i fortsatt forskning om kontextualiserad grammatikundervisning.

Slutligen innebär även utgångspunkten i ett skönlitterärt textutdrag, som eleverna redan är bekanta med, att grammatiken får ett sammanhang (jfr Myhill et al., 2020). När elever enbart får använda sin grammatiska kunskap vid exempelvis satslösning av tillrättalagda exempelmeningar utsätts de inte nödvändigtvis för uppgifter som kräver att de kan applicera den grammatiska kunskapen. I resonemangen kan eleverna inte enbart förlita sig på hänvisning till memorerade begrepp, vilket kan förklaras mot bakgrund av att eleverna analyserar en autentisk text som utmanar dem att snarare deskriptivt utforska språket, där de tillsammans måste testa olika tillvägagångssätt för att hitta en gemensam lösning. I stället för konstruerade meningar avsedda för exempelvis satslösning erbjuder den skönlitterära texten andra ingångar där ett brett spektrum av metasyntaktiska resonemang kan äga rum (jfr Cushing, 2018). Elevernas metalingvistiska aktiviteter med det skönlitterära textutdraget som utgångspunkt kan fungera som en meningsfull ingång till att diskutera olika språkliga nivåer i undervisningen och hur lärare och elever kan närma sig dessa. De olika tillvägagångsätten som det skönlitterära textutdraget aktualiserar resulterar i en förhandling inom grupperna, vilken sedan kan utgöra en grund i undervisningen för att diskutera språkliga konventioner och nå fördjupade kunskaper om språk. 
Skönlitterära texter kan således synliggöra språkliga strukturer i en viss kontext och genom ett gemensamt utforskande kan elever utveckla sin språkliga medvetenhet (jfr Carter, 2003). När skrivproduktion inte är slutmålet med uppgiften tydliggörs även betydelsen av språket som ett fenomen värt att studera i sin egen rätt. På så sätt har denna studie bidragit med ökade insikter om metalingvistiska aktiviteter som möjlig kunskapsproduktion inom grammatikundervisning. Empirin i denna studie är visserligen begränsad och representerar endast ett urval, men samtidigt överensstämmer kategorierna delvis med tidigare studier om elevers metasyntaktiska resonemang (t.ex. Boivin, 2018; Watson \& Newman, 2017). Resultatet pekar ändock på att det finns ett behov av fortsatt forskning å ena sidan vad gäller elevers sätt att närma sig språkliga strukturer och hur lärare å andra sidan hanterar dessa i undervisningen.

\section{Författarbiografi}

Agnes Strandberg är doktorand i Svenska med didaktisk inriktning och intresserar sig särskilt för grammatikundervisning i svenskämnet. Hon är verksam vid Luleå tekniska universitet och arbetar för närvarande med ett designbaserat forskningsprojekt där en kontextualiserad grammatikundervisning testas och utvecklas tillsammans med svensklärare på gymnasiet. Agnes har tidigare arbetat som gymnasielärare i svenska, historia och svenska som andraspråk.

Outi Toropainen är fil.dr. (2008, Åbo Akademi, Finland) och lektor i Svenska med didaktisk inriktning vid Luleå tekniska universitet sedan 2018. Hennes forskning berör bland annat bedömning av språkkunskaper, processande och inlärning av helsekvenser (formulaic sequences) i olika L2, språkinlärning och flerspråkig identitet. Hon har arbetat tidigare vid tre olika universitet i Finland och samarbetar fortfarande med flera kolleger vid dem.

\section{Referenser}

Arseneau, R., Foucambert, D. \& Lefrançois, P. (2018). Improving the mastery of relative clause in French L1 secondary classes: The effects of an intervention based on verbal interactions on written syntactic structures. L1 Educational Studies in Language and Literature, 18, 1-29. https://doi.org/10.17239/ L1ESLL-2018.18.01.08

Bazeley, P. \& Jackson, K. (2013). Qualitative data analysis with NVivo (2 uppl.). Sage.

Berry, R. (2015). Grammar myths. Language Awareness, 24(1), 15-37.

Boivin, M. C. (2018). A review of the current empirical research on grammar instruction in the francophone regions. L1 Educational Studies in Language and Literature, 17, 1-48. https://doi.org/10.17239/ L1ESLL-2018.18.04.03

Brøseth, H. \& Nygård, M. (2019). Grammatikkdidaktikk. I H. Brøseth, K. M. Eide \& T. A. Åfarli (Red.), Språket som system: Norsk språkstruktur (s. 337-369). Fagbokforslaget.

Camps, A. \& Fontich, X. (2019). Teachers' concepts on the teaching of grammar in relation to the teaching of writing in Spain: A case study. L1 Educational Studies in Language and Literature, 19, 1-36. https://doi. org/10.17239/L1ESLL-2019.19.02.02

Carter, R. (2003). Language awareness. ELT journal, 57(1), 64-65.

Cushing, I. (2018). Stylistics goes to school. Language and Literature, 27(4), 271-285. 


\section{A. Strandberg $\mathcal{E}$ O. Toropainen}

Denham, K. (2020). Positioning students as linguistic and social experts: Teaching grammar and linguistics in the United States. L1 Educational Studies in Language and Literature, 20, 1-16. https://doi.org/10.17239/ L1ESLL-2020.20.03.02

Fontich, X. (2014). Grammar and language reflection at school: Checking out the whats and the hows of grammar instruction. I T. Ribas, X. Fontich \& O. Guasch (Red.), Grammar at school: Research on metalinguistic activity in language education (s. 255-284) Peter Lang.

Fontich, X. \& Camps, A. (2014). Towards a rationale for research into grammar teaching in schools. Research Papers in Education, 29(5), 598-625. https://doi.org/10.1080/02671522.2013.813579

Fontich, X. \& García-Folgado, M. J. (2018). Grammar instruction in the Hispanic area:The case of Spain with attention to empirical studies on metalinguistic activity. L1 Educational Studies in Language and Literature. 18, 1-39. https://doi.org/10.17239/L1ESLL-2018.18.04.02

Funke, R. (2018). Working on grammar at school: Empirical research from German-speaking regions. L1 Educational Studies in Language and Literature, 17, 1-39.

Gombert, E. J. (1992). Metalinguistic development. Harvester Wheatsheaf.

Hansson, F. (2009). Tala om text: Om gymnasieelevers metaspråk i gruppsamtal. [Licentiatuppsats]. Malmö högskola.

Hsieh, H. F. \& Shannon, S. E. (2005). Three approaches to qualitative content analysis. Qualitative Health Research, 15(9), 1277-1288.

Hultman, T. G. (2003). Svenska Akademiens språklära. Svenska Akademien.

Jackson, S. (2018). Silvervägen. Månpocket.

Kabel, K. \& Bjerre, K. (2020). Kontekstualiseret grammatikundervisning - hvad er det? Viden om Literacy, 27, 20-28.

Kabel, K., Christensen, M. V. \& Brok, L. S. (2021). A focused ethnographic study on grammar teaching practices across language subjects in schools. Language, Culture and Curriculum, 34, 1-16. https://doi.org/ 10.1080/07908318.2021.1918144

Lundin, B. (2004). Icke satsformade meningar i modern tidningsprosa. Språk E Stil, 14, 89-136.

Malmberg, A. (2020). Grammatikövningar i läromedel för svenska 1. I M. Johansson, B. G. Martinsson \& S. P. Swärd (Red.), Bildning, utbildning, fortbildning. Trettonde nationella konferensen $i$ svenska med didaktisk inriktning (s. 160-175). Linköpings universitet.

Myhill, D. (2000). Misconceptions and difficulties in the acquisition of metalinguistic knowledge. Language and Education, 14(3), 151-163.

Myhill, D. (2012). The ordeal of deliberate choice: Metalinguistic development in secondary writers. I V. W. Berninger (Red.), Past, present, and future contributions of cognitive writing research to cognitive psychology (s. 247-274). Psychology Press.

Myhill, D. (2019). Linguistic choice as empowerment. Utbildning $\mathcal{E}$ demokrati, 28(2), 55-75.

Myhill, D. A., Jones, S. M., Lines, H., \& Watson, A. (2012). Re-thinking grammar: The impact of embedded grammar teaching on students' writing and students' metalinguistic understanding. Research Papers in Education, 27(2), 139-166.

Myhill, D., Jones, S., Watson, A. \& Lines, H. (2013). Playful explicitness with grammar: A pedagogy for writing. Literacy, 47(2), 103-111.

Myhill, D., Newman, R. \& Watson, A. (2020). Going meta: Dialogic talk in the writing classroom. The Australian fournal of Language and Literacy, 43(1), 5-25.

Schreier, M. (2012). Qualitative content analysis in practice. Sage.

Schreier, M. (2014). Qualitative content analysis. I U. Flick (Red.), The Sage handbook of qualitative data analysis (s. 170-183). Sage.

Schuster, E. H. (2006). A fresh look at sentence fragments. English fournal, 95(5) 78-83.

Skolverket. (2011). Läroplan, examensmål och gymnasiegemensamma ämnen för gymnasieskola. Skolverket.

Strzelecka, E. \& Boström, L. (2014). Lärares strategier i grammatikundervisning $i$ svenska (Utbildningsvetenskapliga studier 2014:2). Mittuniversitetet, Avdelning för utbildningsvetenskap. https://www.diva-portal.org/smash/ get/diva2:790558/FULLTEXT01.pdf

Teleman, U., Hellberg, S., Andersson, E. \& Christensen, L. (1999). Svenska Akademiens grammatik. Svenska Akademien.

Van Rijt, J. \& Coppen, P. A. (2017). Bridging the gap between linguistic theory and L1 grammar education experts' views on essential linguistic concepts. Language Awareness, 26(4), 360-380.

Van Rijt, J. H., de Swart, P. J., Wijnands, A. \& Coppen, P. A. J. (2019). When students tackle grammatical problems: Exploring linguistic reasoning with linguistic metaconcepts in L1 grammar education. Linguistics and Education, 52, 78-88. 
Watson, A. (2012). Navigating 'the pit of doom': Affective responses to teaching 'grammar'. English in Education, $46(1), 22-37$.

Watson, A. M. \& Newman, R. M. C. (2017). Talking grammatically: L1 adolescent metalinguistic reflection on writing. Language Awareness, 26(4), 381-398.

Watson, A. M. Newman, R. M. \& Morgan, S. D. (2021). Metatalk and metalinguistic knowledge: The interplay of procedural and declarative knowledge in the classroom discourse of first-language grammar teaching. Language Awareness. https://doi.org/10.1080/09658416.2021.1905655

Wilson, P. (2000). Mind the gap: Ellipsis and stylistic variation in spoken and written English. Longman. 